\title{
A aplicação da metodologia Paideia no apoio institucional, no apoio matricial e na clínica ampliada
}

\author{
Gastão Wagner de Sousa Campos ${ }^{(a)}$ \\ Mariana Dorsa Figueiredo(b) \\ Nilton Pereira Júnior ${ }^{(\mathrm{c})}$ \\ Cristiane Pereira de Castro ${ }^{(d)}$
}

Campos GWS, Figueiredo MD, Pereira Júnior N, Castro CP. Application of Paideia methodology to institutional support, matrix support and expanded clinical practice. Interface (Botucatu). 2014; 18 Supl 1:983-95.

Through a narrative review, the Paideia theoretical and methodological concept constructed by Campos was updated. In addition, public institutions that have adopted this strategy over the last two decades were indicated. This study analyzed the application and methodological development of the Paideia concept within the administrative space (institutional support), in interprofessional relationships (matrix support) and in clinical practice.

Keywords: Paideia methodology. Institutional support. Matrix support. Expanded clinical practice.
Mediante revisão narrativa, realizou-se atualização da concepção teórico-metodológica Paideia construída por Campos, bem como foram apontadas instituições públicas que adotaram essa estratégia nas duas últimas décadas. Analisou-se sua aplicação e desdobramentos metodológicos no espaço da gestão (apoio institucional), nas relações interprofissionais (apoio matricial) e na prática da clínica.

Palavras-chave: Metodologia Paideia. Apoio institucional. Apoio matricial. Clínica ampliada.

(a,b,d) Departamento de Saúde Coletiva, Faculdade de Ciências Médicas, Universidade Estadual de Campinas (Unicamp). Rua Tessália Vieira de Camargo, 126, Cidade Universitária Zeferino Vaz. Campinas, SP, Brasil. 13083-887 gastaowagner@ mpc.com.br; madorsa@ hotmail.com; crispcastro@gmail.com (c) Faculdade de Medicina, Universidade Federal de Uberlândia. Av. Pará, 1720, Bairro Umuarama. Uberlândia, MG, Brasil. 38400-902. niltonmed@ yahoo.com.br 


\section{Introdução}

A concepção teórica e metodológica Paideia, desenvolvida por Gastão Wagner de Sousa Campos e colaboradores ao longo dos últimos 25 anos, vem sendo amplamente utilizada em políticas e práticas de saúde no Brasil.

Trata-se de uma rede conceitual e metodológica para dar suporte à cogestão de coletivos, que possui três eixos de aplicação:

1 Apoio institucional: é uma função gerencial para a cogestão, usada nas relações entre serviços, e entre gestores e trabalhadores ${ }^{1,2}$;

2 Apoio matricial: sugere um modo de funcionamento para o trabalho em rede, valorizando uma concepção ampliada do processo saúde-doença, a interdisciplinaridade, o diálogo e a interação entre profissionais que trabalham em equipes ou em redes e sistemas de saúde $\mathrm{e}^{1,3-5}$;

3 Clínica ampliada e compartilhada: aplicação da metodologia do apoio Paideia como estratégia para se compartilhar o Projeto Terapêutico entre usuário e profissionais. Objetiva a cogestão do atendimento, da assistência e do cuidado entre profissionais responsáveis e usuários ${ }^{6-9}$.

O objetivo deste artigo é apresentar uma síntese sobre a concepção Paideia e suas aplicações metodológicas. Para isso, realizamos uma revisão narrativa, estratégia considerada adequada para descrever e discutir o desenvolvimento de determinado assunto, do ponto de vista teórico e contextual ${ }^{10}$.

Buscamos resgatar aspectos presentes nas principais publicações dos autores que deram origem à metodologia Paideia e incluir as atualizações elaboradas durante os últimos anos. Também destacamos a incorporação desse referencial por algumas instituições públicas de saúde. Assim, pretendemos sistematizar e atualizar o conhecimento sobre o tema, produzindo uma fonte didática e contribuindo para a difusão de propostas que visem ao desenvolvimento das práticas em saúde no SUS ${ }^{(e)}$.

\section{Usos institucionais do referencial Paideia no SUS}

A metodologia Paideia de cogestão das instituições e do cuidado em saúde teve suas primeiras aplicações no Sistema Único de Saúde do município de Campinas/SP, durante a década de 1990. Serviços de saúde mental, de Atenção

Básica e da área hospitalar sofreram mudanças organizacionais em que se construíram, orientados por esse referencial, novos arranjos e dispositivos de gestão e do processo trabalho, especialmente os denominados "apoio institucional", "equipes de referência" e "apoio matricial", que serão descritos a seguir. Buscava-se, com isso, a democratização institucional e a qualificação do atendimento à população. Nos anos seguintes, várias cidades incorporaram modos de realizar o apoio institucional e matricial, bem como foram valorizados os conceitos de clínica ampliada e compartilhada. Belo Horizonte/MG, Quixadá/ CE, Sobral/CE, Recife/PE, Aracaju/SE, Rio de Janeiro/RJ, Viamão/RS, Rosário/ Argentina - em várias localidades se experimentaram essas diretrizes e metodologias.

A partir de 2003, o Ministério da Saúde iniciou um processo de formulação e implementação do apoio institucional aos estados e municípios. Nesse primeiro momento, com dois enfoques: apoio à gestão descentralizada do SUS - coordenado pelo Departamento de Apoio à Descentralização (DAD) da Secretaria Executiva ${ }^{11}$ - e apoio à mudança dos modelos de gestão e atenção dos sistemas e serviços de saúde - coordenado pela Política Nacional de Humanização

\footnotetext{
(e) Este estudo

não apresentou a necessidade de aprovação por Comitê de Ética em Pesquisa, uma vez que manipula dados de livre acesso, não se tratando, portanto, de documentos que requeiram sigilo ético. As demais questões éticas foram preservadas, na medida em que todos os autores consultados foram devidamente referenciados no texto.
} 
- Humaniza/SUS ${ }^{12}$. Um segundo movimento do Ministério da Saúde na implementação do apoio institucional se deu a partir de 2011, nesse momento, buscando a articulação das diversas secretarias e departamentos, chamado Apoio Institucional Integrado ${ }^{13}$, coordenado pelo Núcleo Gestor do Apoio Integrado (composto por todas as secretarias do Ministério e coordenado pela Secretaria Executiva).

Em seguida, algumas Secretarias de Estado da Saúde também criaram núcleos de apoiadores institucionais para realizar a relação com as secretarias e serviços municipais, destacando-se a Superintendência de Atenção Básica do Rio de Janeiro, a Diretoria de Atenção Básica da Bahia e Fundação Estatal de Saúde da Família da Bahia.

Em 2008, após um longo período de debate, o Ministério da Saúde publicou uma nova política denominada de Núcleos de Apoio à Saúde da Família (Nasf), cujo programa e manual de orientação se basearam na estratégia do apoio matricial ${ }^{14,15}$.

As equipes de Nasf são compostas por profissionais de áreas especializadas, que têm como função principal apoiar um conjunto de Equipes de Saúde da Família, para que estas ampliem a abrangência de suas ações e aumentem sua resolutividade. Esse suporte técnico especializado pode ocorrer a partir de discussões clínicas; intervenções conjuntas com a Equipe de Saúde da Família (consultas, visitas domiciliares, grupos, etc.); e assistência direta aos casos que demandam ações especializadas. Atualmente, existem 1.971 Nasfs em 1.359 municípios ${ }^{16}$, sendo São Paulo, Belo Horizonte, Rio de Janeiro, Recife, Curitiba, Fortaleza e João Pessoa os municípios que mais avançaram na construção de Nasfs.

A concepção da clínica ampliada e compartilhada também foi incorporada ao discurso oficial do Ministério da Saúde, particularmente nos documentos fundadores da Política Nacional de Humanização ${ }^{12,17}$ e na Política Nacional de Atenção Básica ${ }^{18}$.

\section{Concepção teórica e metodológica Paideia}

Na tese de livre-docência, intitulada "Um método para análise e cogestão de coletivos - a constituição do sujeito, a produção de valor de uso e a democracia nas instituições: o Método da Roda", Campos ${ }^{1}$ realizou uma crítica à racionalidade gerencial hegemônica e indicou um método que busca favorecer a democratização da gestão nas organizações, por meio da formação de coletivos organizados, voltados para a produção de bens ou serviços, e do incentivo à participação dos sujeitos na gestão da organização e de seus processos de trabalho. Para tanto, o método parte de uma articulação de saberes e práticas dos campos da Saúde Coletiva, da clínica, da política, da administração e planejamento, da psicanálise, da análise institucional e da pedagogia¹.

O termo Paideia é de origem grega. Designa um dos três componentes essenciais da democracia ateniense: Cidadania, direitos das pessoas; Ágora, espaço para compartilhar poder; e o conceito Paideia, educação integral.

O Método Paideia (ou método da roda, como também é conhecido) realiza uma adaptação dessa tríade. Busca-se o efeito Paideia: que é o trabalho realizado para ampliar a capacidade das pessoas para lidar com informações, interpretá-las, compreender a si mesmas, aos outros e ao contexto. Em consequência, pretende contribuir para o desenvolvimento da capacidade de tomar decisões, lidar com conflitos, estabelecer compromissos e contratos; ampliando, enfim, a possibilidade de ação dessas pessoas sobre todas essas relações.

O método procura analisar a dinâmica do desejo e do interesse próprio, estimulando, ao mesmo tempo, que se considere o desejo e interesse dos outros em uma dinâmica histórica e social. $\mathrm{O}$ método Paideia é um esforço para sistematizar modos de intervir de forma deliberada nessa dinâmica, reconhecendo que o controle sobre esse processo será sempre parcial, já que há inúmeros fatores produzindo efeitos sobre pessoas e instituições.

A concepção teórica e metodológica Paideia busca compreender e interferir nas dimensões do poder, do conhecimento e do afeto. E pode ser aplicada à política, gestão, pedagogia, Saúde Coletiva e clínica. A política e a gestão tratam de modos para operar com o poder; a pedagogia, com o conhecimento; a clínica da subjetividade, com o afeto. 
Esses campos disciplinares, contudo, separam essas três dimensões, quando na realidade elas atuam de forma conjugada e simultânea. A constituição de sujeitos, das necessidades sociais e das instituições é um produto de relações de poder, do uso de conhecimentos e de modos de circulação de afetos. A metodologia Paideia objetiva ampliar a capacidade das pessoas de lidarem com poder, com circulação de saberes e afetos; ao mesmo tempo que estão fazendo coisas, trabalhando, cumprindo tarefas, aprendendo ou sendo cuidadas por equipes de saúde. Essa concepção preconiza a reforma das organizações de saúde com base na cogestão, ou seja, o estabelecimento deliberado de relações dialógicas, com compartilhamento de conhecimentos e de poder.

A concepção Paideia parte da constatação da diferença constitutiva e essencial entre os distintos atores sociais (gestores, trabalhadores e usuários), tanto do ponto de vista de papel social quanto de poder. Não há paridade mesmo quando se constitui espaços coletivos com vistas ao diálogo. Mas pretende-se estabelecer contratos entre os envolvidos, de modo a permitir que a abordagem das questões relativas à clínica e à gestão possa ser construída desde os diferentes saberes e interesses.

O apoio não é um lugar estrutural específico. Consideremos alguns núcleos estruturais de onde se costuma realizar apoio, cada um deles com vantagens e limitações específicas:

- de um lugar de poder institucional: um dirigente (de organizações, equipes, movimentos, etc.) pode apoiar quem opera no cotidiano, desde que esteja em uma estrutura que pressupõe a cogestão. É evidente que a análise das implicações de um gestor com a instituição e com a política oficial é, em geral, grande, o que tende a posicionar esses atores sociais mais do lado da organização, do projeto institucional, do que dos trabalhadores ou usuários. De qualquer modo, todo sistema de cogestão condiciona o gestor a utilizar metodologias de apoio para viabilizar o governo;

- de um lugar de suposto saber e como alguém externo ao agrupamento: um especialista que é demandado em função de um conhecimento presumido (assessor, supervisor, alguém com domínio de um método, ou de alguma experiência prévia, analista ou apoiador institucional). O modo para se apoiar um grupo a partir desse lugar tem muitas semelhanças com a supervisão clínico-institucional utilizada em Saúde Mental;

- de um lugar de suposto saber e, ao mesmo tempo, de poder profissional (clínico, pedagogo, sanitarista, etc.) pode-se realizar práticas profissionais de maneira compartilhada com os usuários. Trata-se do uso da metodologia de apoio na relação clínica;

- de um lugar de paridade (suposta horizontalidade) no coletivo: um membro da equipe ou de uma área específica assumiria a função de apoiador Paideia para seus pares. Aqui se trata do denominado apoio matricial.

\section{Apoio institucional e cogestão}

A cogestão é o exercício compartilhado do governo de um programa, serviço, sistema ou política. O exercício compartilhado de governo implica em coparticipação de sujeitos com distintos interesses e diferentes inserções sociais em todas as etapas do processo de gestão: definição de objetivos e de diretrizes, diagnóstico, interpretação de informações, tomada de decisão e avaliação de resultados.

Espaço coletivo é o lugar organizacional em que ocorrem encontros entre sujeitos com distintos interesses e papéis institucionais, construindo oportunidade para análise e tomada de decisão sobre temas relevantes. O método Paideia propõe-se a construir ativamente espaços com essas finalidades, integrando-os em sistema de gestão participativa segundo vários planos.

Há espaços coletivos estruturados e inscritos nos organogramas das organizações. É o caso dos Conselhos de Saúde previstos no SUS, espaço de cogestão em que haverá participação de usuários, trabalhadores de saúde e de gestores. A metodologia sugere a ampliação desses espaços permanentes de cogestão, criando-se colegiados de gestão, em que haverá participação de gestores e de trabalhadores; equipes de referência, em que haverá participação somente dos trabalhadores. Todos esses espaços coletivos, para funcionarem em cogestão, devem ter um caráter deliberativo, isto é, devem permitir a tomada de decisões por parte dos atores envolvidos em cada uma dessas instâncias. Podem ainda ser construídos espaços coletivos de caráter eventual, dependentes do contexto e da necessidade - dispositivos eventuais como oficinas, assembleias, seminários, etc. Encontros cotidianos 
entre distintos sujeitos podem ser tomados como espaços coletivos de cogestão, desde que ocorra análise sobre um tema e tomada de decisões.

A democracia institucional depende da instituição de sistemas de cogestão, da construção de espaços coletivos em que a análise de informações e a tomada de decisão ocorram de fato. Objetiva incluir a sociedade civil na gestão do Estado e das instituições, e compartilhar o poder com as equipes de trabalho na gestão de organizações produtoras de bens ou serviços. Essa reforma do modelo de gestão é sugerida tanto em função de valores democráticos, quanto por reconhecer que diante de cada núcleo de poder político ou gerencial, há contrapoder de usuários e de trabalhadores, com os quais há que se relacionar em esquemas de luta e negociação, objetivando a construção de compromissos e de contratos.

O apoio institucional é um recurso metodológico que busca reformular os tradicionais mecanismos de gestão. Trata-se de um modo para fazer cogestão. Pressupõe postura interativa, tanto analítica quanto operacional. É uma função que pode ser exercida tanto pelo gestor, quanto pode constituir um cargo específico, uma vez que várias instâncias do SUS já contam com grupos de apoiadores institucionais. Não se trata de uma proposta que busque suprimir outras funções gerenciais como a de coordenação, planejamento, direção. Ela busca um modo complementar para realizar essas funções e, em particular, altera a maneira de realizar coordenação, planificação, supervisão e avaliação do trabalho. Em geral, essas funções são exercidas com um importante grau de distância entre os responsáveis pela gestão e os operadores de atividades finais.

Em resumo, poder-se-ia afirmar que o recurso de apoio institucional procura escapar à tendência comum de várias escolas de gerência que intervêm sobre os trabalhadores, mas não atuam de maneira interativa com eles. Na realidade, considera-se que o saber gerencial não escapou à tendência predominante em ciência de supor uma relação quase asséptica entre aqueles que exercem funções de condução e os executores de tarefas. Uma reiteração da separação entre o sujeito do conhecimento e do poder e o objeto a ser conhecido e manipulado.

O apoio parte da pressuposição de que as funções de gestão se exercem entre sujeitos, ainda que com distintos graus de saber e de poder. Em muitas situações concretas, a capacidade de governo é baixa, tendo em vista o grau de poder dos atores. Exemplo é a relação entre entes federados no SUS; apesar de ser denominado de sistema único, funciona com importante grau de autonomia dos municípios e dos estados. Outro caso é a relação entre gestores e equipes na saúde; em geral, os médicos conservam importante grau de autonomia no exercício cotidiano de suas tarefas. Observase processo semelhante nas organizações públicas em geral e nas de ensino, em particular. Em todos esses casos a gestão necessita estabelecer compromissos e contratos com profissionais ou com entes componentes de uma rede operacional. O apoio pressupõe a cogestão, isto é, negociação, mediação de conflitos, composição articulada de projetos, planos, mas pressupõe também ajuda para que os agentes consigam cumprir com os vários compromissos. O processo de apoio objetiva também cuidar da formação Paideia, ampliada, dos sujeitos envolvidos. Formação Paideia envolve várias dimensões: a cognitiva, a afetiva, a política, lidar com paixões, com conflitos, com a alienação, com resistências inconscientes, etc.

Todo trabalho, todo projeto, toda política, tem, pelo menos, uma tripla finalidade, e produz efeitos em vários sentidos distintos. Primeiro: objetiva a produção de bens ou serviços para pessoas que utilizam a organização - se trabalha para o outro; segundo: procura assegurar a reprodução ampliada da própria organização; e terceiro: termina interferindo na produção social e subjetiva dos próprios trabalhadores e dos usuários. A gestão tradicional, ao lidar com os trabalhadores e com os usuários como objetos, centra esforços na reprodução social da própria organização, descuidando dos demais.

$\mathrm{Na}$ realidade, ao não reconhecer que toda gestão é produto de uma interação entre pessoas, verifica-se, com frequência, uma tendência à reprodução de formas burocratizadas de trabalho, com empobrecimento subjetivo e social dos trabalhadores e dos usuários.

O apoio institucional é uma estratégia metodológica que procura compatibilizar essas três finalidades, reconhecendo que a gestão produz efeitos sobre os modos de ser e de proceder dos trabalhadores e de usuários das organizações. 


\section{Apoio matricial e equipe de referência}

O apoio matricial e a equipe de referência são tanto arranjos organizacionais, como uma metodologia para fazer algo. Foram imaginadas e experimentadas como forma para se operar em redes ou em sistemas complexos. Pretendem construir um modo de operar o trabalho a partir de diretrizes nem sempre fáceis de compatibilização. Em primeiro lugar, busca levar a lógica da cogestão e do apoio para as relações interprofissionais, substituindo as tradicionais modalidades de relação burocrática e com grande desequilíbrio de poder. $\mathrm{Na}$ saúde, tenta criticar e reconstruir a tal da "interconsulta" e dos "sistemas de referência e contrarreferência". Em segundo lugar, reconhecendo a complexidade dos processos sociais, sanitários ou pedagógicos, busca pensar modos de se lidar com esses processos segundo o referencial da interdisciplinaridade e da interprofissionalidade. Procura, portanto, a constituição de equipes multiprofissionais para o enfretamento de problemas sem, contudo, perder-se o padrão de responsabilização e compromisso com a produção de saúde. Trata-se de uma proposta de mudança do arranjo organizacional e das responsabilidades profissionais e gerenciais, de modo a facilitar a cogestão em locais onde é necessário um trabalho em equipe.

A equipe de referência é um tipo de arranjo contratual que busca mudar o padrão dominante de responsabilidade nas organizações: no lugar das pessoas se responsabilizarem predominantemente por atividades e procedimentos (geralmente uma responsabilidade quantitativa), busca-se construir a "responsabilidade de pessoas por pessoas"(f). Ou seja, formar um "time" em que os trabalhadores tenham uma clientela sob sua responsabilidade: uma equipe responsável por certo número de leitos em um hospital ou, como no caso da Equipe de Saúde da Família - ESF, uma equipe responsável por uma clientela adscrita, pertencente a dado território.

No arranjo equipe de referência, a definição de clientela possibilita a construção do vínculo, a relação terapêutica longitudinal e o acompanhamento do processo saúde-doença-atenção de cada usuário ${ }^{5}$. Isso faz com que a equipe conheça na singularidade o modo de viver do sujeito e sua história de vida, colocando-se como corresponsável pelo tratamento. A marca central desse arranjo é o fato de a equipe de referência, por meio de um plano compartilhado, tomar para si o acompanhamento do paciente em suas diferentes facetas além da biológica, como os âmbitos sociais, familiares, políticos, psíquicos, entre outros.

A equipe de referência procura enfrentar a herança da "linha de produção" taylorista nas organizações de saúde. Mas não é somente a definição de uma clientela que define a equipe de referência. É também outra distribuição de poder na organização: a coordenação interdisciplinar. Ou seja, na lógica da organização taylorista-fayolista, o poder gerencial está atrelado ao saber disciplinar fragmentado e as chefias se dividem por corporações e não por coordenações de equipes interdisciplinares (fato evidente ao olharmos o organograma da maior parte das organizações). A presença de uma chefia de enfermagem, outra chefia de médicos e outra ainda de Agentes Comunitários de Saúde, no lugar de uma coordenação para toda a equipe, aumenta a chance de fragmentação do trabalho. As chefias profissionais produzem uma tendência de responsabilidade maior para com uma atividade corporativa do que para com o resultado final da equipe para o usuário. Na prática, essas chefias por corporação reforçam grupalidades corporativas, que desvalorizam ou rivalizam com a grupalidade da equipe. Uma das funções importantes da coordenação da equipe é justamente (f) Esse arranjo é adequado no caso de organizações com produção relacionada às pessoas (saúde, educação, etc.) 
cuidar da construção de uma interação positiva entre os profissionais, construindo objetivos e objetos comuns, apesar das diferenças (e não contra as diferenças).

O fio condutor do trabalho de uma equipe de referência é o compartilhamento de saberes, competências, responsabilidades e ações. Os conceitos de campo e núcleo ${ }^{1}$ são úteis para compor a interdisciplinaridade, sem diluir a especificidade dos saberes. Eles permitem distinguir os saberes e práticas peculiares a cada profissão, dos saberes, práticas e responsabilidades comuns a todos os profissionais de saúde. No núcleo haveria uma aglutinação de conhecimentos e práticas, conformando as identidades profissionais e determinados padrões de compromisso com a produção de saúde: os saberes, práticas e responsabilidades peculiares aos médicos, ou aos enfermeiros, ou aos Agentes Comunitários de Saúde, psicólogos, assistentes sociais. Já o campo seria um espaço de interseção entre os saberes, em que haveria uma sobreposição dos limites entre cada especialidade e cada prática, e onde todo profissional de saúde deveria atuar, independentemente de sua categoria ou formação.

Para atuar no campo, cada profissão buscaria apoio em outras áreas para cumprir suas tarefas, reforçando então a interdisciplinaridade. Esse é o fundamento do arranjo apoio matricial: os profissionais das áreas especializadas, que não participam cotidianamente da equipe de referência, oferecem suporte técnico especializado a essas equipes. Seria uma oferta de um núcleo especializado ao campo interdisciplinar da equipe de referência. Esse arranjo pretende assegurar, de um modo dinâmico e interativo, a retaguarda especializada às equipes de referência, modificando a lógica do encaminhamento, centrada no sistema de referência e contrarreferência ${ }^{5}$.

É relevante mencionar que, em 2008, o Ministério da Saúde criou os Núcleos de Apoio a Saúde da Família - Nasf ${ }^{15}$, com recurso financeiro destinado especificamente para a contratação de profissionais de apoio para as equipes da ESF. O conceito utilizado na proposta, pela primeira vez na definição de uma portaria do Departamento de Atenção Básica do Ministério, é o de apoio matricial.

O apoio matricial tem uma dimensão de suporte técnico-pedagógico, ou seja, pressupõe apoio educativo para a equipe de referência e ações realizadas conjuntamente com ela. A partir de discussões clínicas conjuntas ou mesmo intervenções concretas junto com as equipes (consultas, visitas domiciliares, grupos), os apoiadores matriciais podem contribuir para o aumento da capacidade resolutiva das equipes, qualificando-as para uma atenção ampliada que contemple a complexidade da vida dos sujeitos. Mas existe também uma dimensão de suporte assistencial, o que demanda do apoiador a realização de ações clínicas diretamente com os usuários. Contudo, o trabalho na lógica matricial permite distinguir os casos e situações que podem ser acompanhadas pela equipe de referência, daquelas demandas que necessitam de uma atenção especializada, a ser oferecida pelos próprios apoiadores matriciais ou, de acordo com o risco, a vulnerabilidade e a gravidade, pelos serviços especializados ou por outras instâncias como assistência social, educação, etc.

Com a composição de uma rede matricial de apoio às equipes de referência seria possível disparar uma série de mudanças na atenção em saúde, na direção da responsabilização, da ampliação da clínica e da interdisciplinaridade: - evitar a fragmentação da atenção, a medicalização e outros danos e iatrogenias provocados pelo "consumo" excessivo de tratamentos, procedimentos e exames; proporcionar coeficientes terapêuticos de acordo com as vulnerabilidades e potencialidades de cada usuário, promovendo com isso maior equidade e ampliando o acesso às demandas de maior gravidade; - construir dispositivos de atenção em resposta às diferentes necessidades dos usuários e estimular a articulação entre os profissionais na elaboração de ofertas para cada situação singular; - romper com a produção de excessivos encaminhamentos às especialidades e produzir corresponsabilização, de modo que o encaminhamento preserve o vínculo e possa ser feito com outra lógica: a do diálogo entre os serviços e os profissionais ${ }^{3}$.

\section{O apoio na relação clínica: a clínica ampliada e compartilhada}

O processo de trabalho em saúde é sempre uma interação intersubjetiva medida pela estrutura das organizações de saúde e das instituições sociais. Em todo trabalho em saúde há o encontro entre sujeitos com importantes diferenças em relação aos seus desejos, interesses, saberes e coeficiente de 
poder. Há uma diferença irredutível entre o profissional e o usuário, por mais horizontal e aberta que seja a relação estabelecida. O profissional deve ser portador de uma oferta técnica, no caso, o saber clínico e sanitário.

A teoria Paideia sugere a ampliação e a reformulação desse conhecimento clínico e sanitário, não seu abandono. O usuário tem um conhecimento privilegiado sobre seu sofrimento e sobre sua própria vida. O interesse do usuário é obter algum tipo de apoio para melhorar seu estado de saúde ou a coletividade. O interesse do profissional relaciona-se, em geral, à sua sobrevivência e realização pessoal. A relação de poder em um espaço clínico ou sanitário será sempre desequilibrada a favor do profissional e da instituição de saúde. Pode-se atenuar essa desigualdade, nunca eliminá-la.

Sugere-se operar com a noção de que todo encontro clínico ou sanitário é um "espaço coletivo"; em que se faz necessária a reflexão sobre esses papéis e responsabilidades distintos. Tal reflexão deve subsidiar linhas de mudança necessárias para reorientar o trabalho clínico e em Saúde Coletiva, buscando a ampliação do seu núcleo de conhecimento e de práticas, e o seu compartilhamento entre trabalhador e usuário. Trata-se de inventar modos de cogestão do ato e do processo clínico e sanitário em geral.

O conceito de clínica ampliada e compartilhada foi formulado por Campos ${ }^{1,9}$ com base em toda uma linhagem de trabalhos de revisão do paradigma biomédico. A biomedicina possui limites, como qualquer saber estruturado que não seja plástico à variação dos casos concretos:

Todo saber tende a produzir certa ontologia do seu objeto, tende a transformar o objeto de análise em um Ser com vida própria. [...] Toda padronização, toda programação e todo planejamento implicam em supor um mundo de regularidades. Um mundo em que as doenças seriam as mesmas em cada uma de suas múltiplas manifestações [...]. Em resumo, aprender sobre uma práxis pressupõe supor casos que se repetiriam mais ou menos iguais. Da ontologia à ortodoxia, no entanto, há apenas um passo. Sobre estas supostas verdades, em geral, organizase todo um sistema de poder, uma hierarquia de guardiões, de fiéis defensores da identidade da ontologia contra a variação da vida. Entretanto, tratados sobre a doença ou sobre a fisiologia padrão dos seres humanos ajuda a clínica. Mais do que a ajudar, a torna possível.

O desafio estaria em passar deste campo de certezas, de regularidades mais ou menos seguras, ao campo da imprevisibilidade radical da vida cotidiana. [...] Como realizar este percurso com segurança? Uma primeira resposta: o reconhecimento explícito dos limites de qualquer saber estruturado já seria uma primeira solução, pois obrigaria todo especialista a reconsiderar seus saberes quando diante de qualquer caso concreto. Sempre. ${ }^{9}$ (p. 65)

A ampliação das práticas clínicas e de Saúde Coletiva pressupõe, de início, desviar o foco de intervenção da doença ou dos procedimentos, para recolocá-lo no sujeito, portador de doenças, mas também de outras demandas e necessidades.

Trata-se, portanto, de operar uma tripla ampliação:

- do objeto de trabalho: incorporando as fragilidades subjetivas e as redes socais, para além dos riscos biológicos; isto é, trabalhar com pessoas e coletivos considerando o interjogo das variáveis em coprodução e das características singulares (capacidade para elaboração de interpretações e posicionamentos, capacidade de estabelecer contratos e compromissos). Isso sem desconsiderar a doença ou os riscos de adoecer;

- dos objetivos do trabalho: além de curar, reabilitar e prevenir danos em pessoas doentes, produzir saúde significa também apoiar o desenvolvimento de maiores graus de autonomia e autocuidado dos sujeitos, de sua capacidade de pensar, agir e criar novos modos de vida para si e novas formas de posicionamento diante da sua saúde e do seu contexto;

- e dos meios de trabalho em saúde: diversificando o repertório de ações, reformulando a relação clínica e os processos de Educação em Saúde. Construir relações baseadas no diálogo, na negociação, no compartilhamento de saberes e poderes, no vínculo e na responsabilização. Construir interdisciplinaridade, trabalhando em equipe, e intersetorialidade, trabalhando em rede. 
Uma clínica ampliada e compartilhada baseia-se na escuta e reconhece o saber, o desejo e o interesse das pessoas, questionando-as sobre os sentidos daquilo que estão vivendo. É uma prática menos prescritiva e mais negociada, que não desconsidera os avanços tecnológicos, nem a importância da qualificação técnica e das recomendações baseadas em evidências ${ }^{9}$. Mas também assume que as doenças e os riscos, a despeito dos padrões e regularidades, e mesmo sendo influenciados pelos planos cultural e socioeconômico, em última instância, encarnam-se em sujeitos concretos. Assim, tanto a prevenção como a terapêutica devem partir das evidências e da avaliação de riscos para negociar com as pessoas em termos de redução de danos: o que é possível neste caso, para este paciente, neste contexto? O exercício da função apoio na relação clínica e nas ações de Saúde Coletiva é um recurso que pretende desenvolver, junto aos sujeitos, maiores graus de responsabilização e autonomia para o cuidado com a saúde.

Entretanto, o exercício da clínica ampliada e compartilhada pressupõe a existência de espaços coletivos, nos quais os profissionais, em equipe, possam exercitar sua capacidade de analisar e intervir em conjunto, refletindo sobre os efeitos de suas práticas, sobre o que se passa na relação entre a equipe e entre a equipe e os usuários, e deliberando coletivamente sobre isso ${ }^{1}$. A gestão, entendida como o modo de operar no cotidiano, seria uma instância fundamental para interferir nos processos de subjetivação dos próprios profissionais ${ }^{19}$, contribuindo para que eles participem da construção do sentido de seu trabalho e se sustentem como coprodutores de saúde junto aos sujeitos e às comunidades.

\section{Recursos metodológicos para o apoio Paideia}

Seja no âmbito do apoio institucional, do apoio matricial ou das relações clínicas e em Saúde Coletiva, há algumas recomendações metodológicas para o exercício da função apoio. São procedimentos e posturas que auxiliam o apoiador a lidar com as relações entre sujeitos de um modo diferente do tradicional. Um modo interativo, um modo que reconhece a diferença de papéis, de poder e de conhecimento, ainda que busque estabelecer relações construtivas entre os distintos atores sociais.

O exercício do apoio sempre irá pressupor a instalação de algum grau de cogestão, de democracia institucional. Trata-se de articular os objetivos institucionais aos saberes e interesses dos trabalhadores e usuários. O termo apoio indica uma pressão de fora, implica trazer algo externo ao grupo: sustentar e, ao mesmo tempo, empurrar o outro.

Então como operar a função Paideia? Como gerenciar, trabalhar em equipe e relacionar-se com usuários segundo essa lógica dialógica?

Algumas observações, anotações sobre nossa tekné, que caracterizam a especificidade metodológica do apoio e da cogestão Paideia:

Primeiro: sempre, em todas essas possibilidades, o apoiador tem que se colocar na roda. Permitir, concordar e, até mesmo, buscar ativamente incluir-se no processo; ou seja, sofrer o efeito Paideia. Para isso é fundamental desmentir a falácia da neutralidade, explicitando o lugar de vinculação de cada um. O que significa colocar em análise as relações de poder, de conhecimento e de afeto envolvidas. Os analistas institucionais denominam esse processo de "análise de implicações". E isso não necessita ocorrer de modo selvagem, tudo ao mesmo tempo, transparência total desde o começo. O grau de aprofundamento dos temas se subordina à tarefa e ao próprio grupo, o que é ou não suportável. Isso se descobre por aproximações sucessivas.

Segundo: a função apoio somente ocorre quando se trabalha com uma duplicidade de objetivos. Toda ação institucional, ou de coletivos, teria uma finalidade externa ao grupo - produzir valores de uso para outros -, e uma interna - ampliar a compreensão e a capacidade operacional dos coletivos. Os trabalhadores, os militantes de um movimento, todos são meios para se conseguir algum resultado, mas, ao mesmo tempo, são também um fim de todo e qualquer empreendimento humano. Essa é a trava de segurança, sem a qual nem se começa a realizar a função apoio. 
Com certeza, o dirigente e o profissional têm dificuldades adicionais para ser coerente com essa diretriz: seu papel estrutural os condiciona a valorizar a produção de valores de uso e também a conservação do próprio poder. No entanto, pode-se compor a lógica desses lugares com o objetivo de constituir sujeitos autônomos, já que operadores mais analíticos costumam ser, em geral, mais eficazes, uma vez que tendem a se envolver de modo criativo com a produção de valores de uso.

Terceiro: trabalhar com as demandas de quem está recebendo apoio, mas também trazer ofertas ao coletivo. E aqui a primeira oferta é se oferecer como apoiador. Explicitar: há um método, há temas prioritários, há não ditos, há resistências, bloqueios, há correlação de forças, há necessidade de se estabelecer contratos com outros interesses, outras culturas, etc. E toda oferta é uma oferta interessada, revela as implicações de poder, afetivas e com os campos de conhecimento do apoiador. Ofertar é revelar-se, é expor-se à avaliação alheia, é um exemplo Paideia, um estímulo para superar a inércia do grupo. Por outro lado, as demandas do grupo funcionam como ofertas ao apoiador, são os degraus onde se apoia para conseguir estabelecer novos compromissos e contratos, mexer com os outros e consigo mesmo.

Valeria aprofundar métodos para ofertar coisas. Há dois campos de oferta: um relativo ao externo, a produção de valores de uso, modos de comprometer-se com os outros, com as instituições, com a realidade. Modelos de atenção em saúde, modelos pedagógicos, modos de organizar o trabalho, os movimentos, etc. Mas comprometer-se de forma crítica, tensionando limites, explorando possibilidades de se fazer tarefas de modo distinto. O outro campo é aquele relativo à ampliação da autonomia do grupo, aprender a circular, a transitar, criar asas, depender menos do apoiador. E aqui outra diretriz Paideia: o apoio somente funciona quando o grupo consegue ampliar suas referências, e mais, quando consegue lidar com essas referências de forma crítica, ou seja, como oferecimentos que podem ou não ser aceitos.

Quarto: apoiar o grupo tanto para construir objetos de investimento, quanto para compor compromissos e contratos com outros. A vida ocorre no meio, sem desfrute do cotidiano não há sentido para a vida. A postura burocrática, o jogar-se tudo no futuro, o ressentimento ou a culpa, a não apropriação de novos conhecimentos, a concentração de poder, todos são fatores ou sintomas que impedem a constituição de objetos de investimento. Uma das tarefas do apoiador refere-se exatamente a capacitar os grupos a depositarem afetos positivos em objetos (coisas) fora de si mesmos, ainda que referenciados pelo desejo e interesse de cada um. Gostar do que se faz, apostar em projetos, em novas relações de afeto e de poder. Desfrutar o prazer de saber. A construção desse objeto de investimento depende de fatores políticos, cognitivos e afetivos. Há que se lidar com esta mescla. Por outro lado, agir em função de outros, estabelecendo compromissos e contratos; ou seja, sem renunciar absolutamente ao desejo ou ao interesse particular. Agir tendo-os como referência, para compor espaços e modos de agir que estabeleçam essas mediações.

Quinto: pensar e fazer junto com as pessoas e não em lugar delas. Para que isso ocorra, não adianta o apoiador imaginar que sabe qual seriam os contratos ou os objetos de investimento mais adequados. É importante que ele procure saber sobre isso, para saber como realizar ofertas. Entretanto, o importante é que ele apoie o grupo para que eles saibam sobre isso, da maneira deles, dialogando com o suposto saber do apoiador.

Sexto: ampliar os espaços onde se aplica o método. Onde se atua de modo Paideia? Em reuniões, com certeza, mas não somente. Fazer junto, estimulando espaços de reflexão. Ofertar experimentando. Misturar o modo de fazer do apoiador com o do grupo. Antes, durante e depois do fazer, analisar, refletir com base nos resultados, com base na prática. O fazer reflexivo é muitas vezes um modo eficaz para quebrar resistências e inseguranças, o que o diálogo teórico jamais resolveria.

Nesse caso, a análise das relações de poder e de afeto depende tanto da capacidade de escuta de outros discursos, quanto de observar os outros fazendo ou sofrendo impactos da prática. Para ampliar a capacidade de análise dos grupos é fundamental que eles aprendam a escutar, a observar e a ler textos teóricos, metodológicos ou de relato de experiências.

Sétimo: autorizar os grupos a exercer crítica generosa e desejar mudanças. As instituições controlam pessoas, as desautorizando a tomar iniciativas que não estejam previstas nos regulamentos. O funcionamento psíquico e as ideologias criam bloqueios ao desejo e mesmo à compreensão de 
si mesmo e das relações sociais. A oferta de temas ou de fragmentos de análise busca ampliar a capacidade dos agrupamentos lidarem com essas interdições: a tarefa de colocar em suspenso temas sagrados, não-ditos, relações veladas, direitos não exercidos, etc.

Oitavo: autorizar-se a ser agente e não somente apoiador. Um dirigente, profissional e mesmo um membro do grupo fazem parte do coletivo ao qual querem apoiar. Já o apoiador institucional vincula-se ao coletivo durante certo período e depois se vai. Nesse sentido tem como função nuclear valer-se do método para trabalhar com o grupo. Os outros não podem durante todo o tempo atuar com base na metodologia Paideia, há momentos em que o dirigente exercerá ações administrativas, o profissional e os membros do grupo tarefas particulares, que lhe dizem mais respeito do que a outros. Nesse sentido, deve-se assegurar espaços de ação em que cumprirão suas funções específicas, ainda quando a avaliação e o desdobramento desses atos possam constituir-se em temas das rodas.

\section{Considerações finais}

Sintetizamos, neste texto, uma proposta que visa à coprodução de sujeitos e coletivos com capacidade de análise e intervenção na realidade, considerando que essa é uma das formas possíveis para a superação dos entraves à mudança nas instituições de saúde. Mudança esta que somente pode ser processada simultaneamente à constituição de novos processos de subjetivação, que se inscrevam numa lógica de coletividade, de alteridade, afirmando o outro como sujeito.

$\mathrm{O}$ apoio aos profissionais visa ao desenvolvimento de uma postura analítica sobre si mesmos, sobre o outro e seu contexto, uma postura crítica e ético-política, para que possam experimentar novas práticas, capazes de responder à complexidade que envolve o trabalho em saúde. Esse apoio busca produzir, simultaneamente, efeitos pedagógicos, terapêuticos e institucionais: pedagógicos - no sentido do aprimoramento do repertório de conhecimentos, dos modos de fazer e pensar dos profissionais, ampliando sua capacidade técnica para intervir; terapêuticos - no sentido da mudança de sujeitos, seus valores e suas visões de mundo; e institucionais - no sentido da mudança nas relações e no contexto de trabalho.

A recriação das relações institucionais, do trabalho em saúde e das formas de estar no mundo dependem, é claro, de uma abertura, de certa disponibilidade e receptividade para o movimento. Tal abertura pode não estar dada a priori, ou seja, pode ser construída em conjunto com os sujeitos e com os grupos. No entanto, em última instância, vale reafirmar o pressuposto contido no método Paideia: não se pretende mudar algo "para" o outro, senão "com" o outro.

\section{Colaboradores}

Os autores trabalharam juntos em todas as etapas de produção do manuscrito. 


\section{Referências}

1. Campos GWS. Um método para análise e cogestão de coletivos. São Paulo: Hucitec; 2000.

2. Oliveira GN. Devir apoiador: uma cartografia da função apoio [tese]. Campinas (SP): Faculdade de Ciências Médicas, Universidade Estadual de Campinas; 2011.

3. Figueiredo MD, Onocko Campos R. Saúde Mental na Atenção Básica à saúde de Campinas (SP): uma rede ou um emaranhado? Cienc Saude Colet. 2009; 14(1):129-38.

4. Campos GWS, Domitti AC. Apoio matricial e equipe de referência: uma metodologia para gestão do trabalho interdisciplinar em saúde. Cad Saude Publica. 2007; 23(2):399-407.

5. Campos GWS. Equipes de referência e apoio especializado matricial: um ensaio sobre a reorganização do trabalho em saúde. Cienc Saude Colet. 1999; 4(2):393-403.

6. Oliveira GN. O projeto terapêutico como contribuição para a mudança das práticas de saúde [dissertação]. Campinas (SP): Faculdade de Ciências Médicas, Universidade Estadual de Campinas; 2007.

7. Onocko Campos R, Campos GWS. Co-construção de autonomia: o sujeito em questão. In: Akerman M, Campos GWS, Carvalho YM, Drumond Junior M, Minayo MCS, organizadores. Tratado de saúde coletiva. São Paulo: Hucitec; 2006. p. 669-88.

8. Cunha GT. A construção da clínica ampliada na Atenção Básica. São Paulo: Hucitec; 2005.

9. Campos GWS. A clínica do sujeito: por uma clínica reformulada e ampliada. In: Campos GWS, organizador. Saúde Paideia. São Paulo: Hucitec; 2003. p. 51-67.

10. Rother ET. Revisão sistemática x revisão narrativa. Acta Paul Enferm. 2007; 20(2):5-6.

11. Ministério da Saúde. Secretaria Executiva. Departamento de Apoio à Descentralização. Apoio integrado à gestão descentralizada do SUS: estratégia para a qualificação da gestão descentralizada. Brasília (DF): SE/DAD; 2004.

12. Ministério da Saúde. Secretaria de Atenção à Saúde. Núcleo Técnico da Política Nacional de Humanização. HumanizaSUS: documento base para gestores e trabalhadores do SUS. Brasília (DF): SAS; 2004.

13. Ministério da Saúde. Secretaria-Executiva. Diretrizes do apoio integrado para a qualificação da gestão e da atenção no SUS/Ministério da Saúde. Brasília (DF): SE; 2011.

14. Ministério da Saúde. Diretrizes do NASF - Núcleo de Apoio à Saúde da Família. Brasília (DF): DAB/SAS/MS; 2009. (Cadernos de Atenção Básica).

15. Portaria $n^{\circ}$ 154, de 24 de Janeiro de 2008. Cria os Núcleos de Apoio à Saúde da Família - NASF. Brasília (DF): MS; 2008.

16. Ministério da Saúde. Portal da saúde [acesso 2013 Abr 29]. Disponível em: http:// www.saude.gov.br/sage

17. Ministério da Saúde. Secretaria de Atenção à Saúde. Núcleo Técnico da Política Nacional de Humanização. HumanizaSUS: a clínica ampliada. Brasília (DF): SAS; 2004.

18. Ministério da Saúde. Política Nacional de Atenção Básica. Legislação em Saúde. Brasília (DF): MS; 2012. (Série E)

19. Onocko Campos R. A gestão: espaço de intervenção, análise e especificidades técnicas. In: Campos GWS, organizador. Saúde Paideia. São Paulo: Hucitec; 2003. p. 122-49. 
Campos GWS, Figueiredo MD, Pereira Júnior N, Castro CP. La aplicación de la metodología Paideia en el apoyo institucional, en el apoyo matricial y en la clínica ampliada. Interface (Botucatu). 2014; 18 Supl 1:983-95.

Mediante la revisión narrativa se realizó la actualización de la concepción teórica y metodológica Paideia construida por Campos, y se mencionaron instituciones públicas que adoptaron esta estrategia en las dos últimas décadas. Se analizó su aplicación y desarrollos metodológicos en el espacio de la gestión (apoyo institucional), en las relaciones interprofesionales (apoyo matricial) y en la práctica clínica.

Palabras clave: Metodología Paideia. Apoyo institucional. Apoyo matricial. Clínica ampliada. 
